\title{
A case of maternal pelvic trauma following a road traffic accident, associated with fetal intracranial haemorrhage
}

\author{
Geoffrey Matthews, Beth Hammersley
}

\begin{abstract}
Maternal pelvic injury resulting from road traffic accidents may cause fetal intracranial haemorrhage. A case is described. Caesarean section should be considered in acute trauma.

(F Accid Emerg Med 1997;14:115-117)
\end{abstract}

Keywords: road traffic accident; pregnancy; fetal intracranial haemorrhage.

Road traffic accidents are major causes of trauma in pregnancy. ${ }^{1}$ Maternal injuries include pelvic fractures, which are associated with fetal intracranial trauma.

Review of published reports over the past 30 years suggests a high fetal death rate in association with fetal intracranial trauma in such circumstances. ${ }^{1-3} \mathrm{~A}$ case is presented of pelvic acetabular fracture in late pregnancy with associated fetal intracranial injury, following a road traffic accident. In the case presented, the fetus was delivered by caesarean section soon after arrival in the accident and emergency (A\&E) department.

This type of pelvic fracture is an uncommon injury in pregnancy, having been reported on only two previous occasions. ${ }^{2-4}$ The mechanism of fetal and maternal injury is discussed.

\section{Case report}

A 31 year old woman was brought to the $A \& E$ department after a road traffic accident. She was 39 weeks pregnant in her third pregnancy. The pregnancy had been uneventful to date. Her first pregnancy, in 1987, had been uncomplicated, resulting in a normal vaginal delivery at term of a $4.3 \mathrm{~kg}$ male. Her second pregnancy was electively terminated in the first trimester.

The patient had been driving the car which collided with another vehicle. Her vehicle was fitted with the standard lap-sash seat belts, which she was wearing. The other vehicle hit the driver's side door, briefly trapping her in it before she was released by the emergency services. She was attended at the scene by a paramedic crew, and a local general practitioner. Her neck was stabilised in a hard collar, and a 14 gauge intravenous cannula sited. No intravenous fluids were begun because of her stable condition. Entonox was given for analgesia en route to the $A \& E$ department.

On arrival the she was immediately transferred to the resuscitation area and managed according to the advanced trauma life support procedure of the American College of Surgeons. Her airway was intact, and she was able to speak (complaining of severe pain in her right hip). Her blood pressure was $150 / 90$ and she had a pulse of 110 beats/min. There was no clinical evidence of abdominal, chest, or head injury, and there was no history of head injury or loss of consciousness. Cervical spine, chest $x$ ray, and $x$ ray of the right femur were all normal. The patient had noticed fluid draining vaginally since the accident and was now contracting 1 in 4 . There was pain on any attempt at moving the right leg, particularly in the region of the right hip; the other limbs were normal. The uterine fundus was soft (between contractions), with a symphysial-fundal height consistent with 39 weeks. The fetal heart was present at a rate of 160 .

Radiological examination of the pelvis showed a comminuted right acetabular fracture. The fetal skull was engaged in the pelvis, with possible fractures evident over the parietal and occipital areas (fig 1).

Vaginal examination revealed the cervix to be $4 \mathrm{~cm}$ dilated, almost fully effaced and the vertex $1 \mathrm{~cm}$ above the level of the ischial spines. Faintly blood stained liquor was draining. Pethidine $100 \mathrm{mg}$ was given intramuscularly for analgesia (in retrospect the intravenous route may have been more appropriate). Six units of blood were cross matched; the haemoglobin on admission was $12.9 \mathrm{~g} / \mathrm{dl}$.

In view of the possible fetal skull fracture it was decided to deliver the baby by emergency caesarean section. This was done under spinal anaesthesia. No uterine or other intraabdominal trauma was noted at the time of operation.

A pale floppy female infant was delivered with an Apgar score of one. Initial resuscitation with oxygen by bag and mask and intramuscular naloxone produced a rapid improvement with the Apgar score of 8 at eight minutes. A large swelling over the left parietal area was evident clinically. Intravenous human albumen $4.5 \%, 35 \mathrm{ml}$, and concentrated red cells, $40 \mathrm{ml}$, were given and the infant transferred to the neonatal surgical unit for respiratory management.

Computerised tomography showed a large subdural haematoma in the left temporal area, with compression of the ventricles (fig 2). Sixty millilitres of blood were evacuated from the subdural space in theatre, and she was given a further $60 \mathrm{ml}$ of fresh frozen plasma.

She was ventilated and sedated, and monitored with an intracranial pressure transducer. 


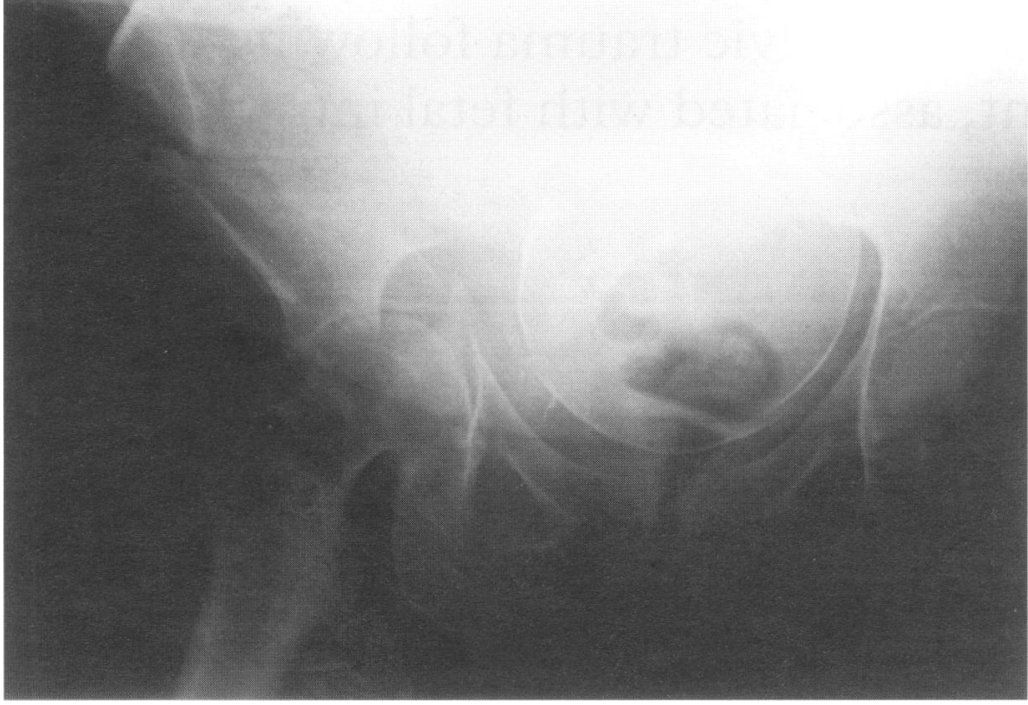

Figure 1 Anteroposterior $x$ ray of the pelvis showing comminuted right acetabular fracture of the pelvis. There are possible fetal skull fractures over the parietal and occipital areas.

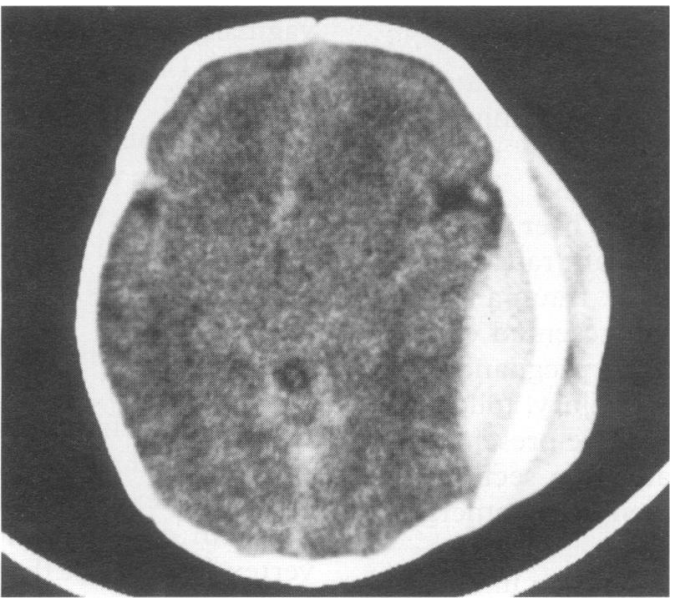

Figure 2 Neonatal computerised tomography scan of the head showing a left subdural haematoma.

At 36 hours she had two grand mal seizures and phenobarbitone was started. No further seizures occurred, and she was extubated on day 4. Subsequent progress was uneventful, and at one week of age she was moving all limbs normally. At six weeks of age she had normal milestones.

The maternal injuries were managed by the insertion of a Denham pin in the right tibia to enable downward traction, and insertion of a percutaneous screw into the right hip to enable lateral traction. Postoperative haemoglobin was $10.4 \mathrm{~g} / \mathrm{dl}$ on day 1 , and she did not require a blood transfusion at any stage. She began mobilising with crutches at 6 weeks, and was discharged home at 8 weeks.

\section{Discussion}

Road traffic accidents account for the majority of trauma cases occurring during pregnancy. ${ }^{1}$ Dyer and Barclay ${ }^{2}$ note that maternal pelvic fracture was an uncommon injury before the widespread use of cars, as it is an injury usually associated with great force. These authors reviewed 53 cases of severe maternal trauma in pregnancy in the State of Louisiana over the preceding 30 years, including 30 cases involving road traffic accidents (table 1 ). Twelve
Table 1 Outcomes in 30 cases of maternal automobile trauma in Louisiana, from Dyer and Barclay (1962)

\begin{tabular}{|c|c|c|}
\hline Type of injury & Number & Outcome \\
\hline Pelvic fracture & 10 & $\begin{array}{l}3 \text { LSCS ( } 1 \text { fetal skull fracture) } \\
115 \text { week miscarriage, } 8 \text { term } \\
\text { vaginal livebirths }\end{array}$ \\
\hline Other fracture & 11 & $\begin{array}{l}1 \text { maternal and fetal death, } 1 \\
20 \text { week miscarriage, } 9 \text { term } \\
\text { vaginal livebirths }\end{array}$ \\
\hline $\begin{array}{l}\text { Pelvic and other } \\
\text { fracture }\end{array}$ & 2 & $\begin{array}{l}1 \text { term vaginal livebirth, } 1 \\
\text { postmortem LSCS (stillborn } \\
\text { fetus) }\end{array}$ \\
\hline Abdominal visceral & 2 & 2 term vaginal livebirths \\
\hline $\begin{array}{l}\text { Other (including } \\
\text { concussion) }\end{array}$ & 5 & $\begin{array}{l}127 \text { week stillborn (preterm } \\
\text { labour), } 140 \text { week stillborn } \\
\text { (abruption), } 138 \text { week } \\
\text { stillborn (intracranial } \\
\text { haemorrhage), } 2 \text { term vaginal } \\
\text { livebirths }\end{array}$ \\
\hline
\end{tabular}

LSCS, lower segment caesarean section

maternal pelvic fractures were described, two in which there were fetal cranial injuries. One case was of a fetal skull fracture following a road traffic accident at 37 weeks' gestation, with subsequent delivery of a live infant at caesarean section. The second case involved a patient at 36 weeks with serious injuries, including pelvic fracture, maternal death occurring soon after arrival in hospital. Postmortem caesarean section in casualty produced a stillborn infant with cerebral haemorrhage. Stafford et $a l^{1}$ reviewed eight cases of lethal fetal intrauterine trauma. In two of their cases there was a maternal pelvic fracture, one of which was associated with a fetal basilar skull fracture, the other with a subdural haematoma in the fetus. A three point restraint was being worn in the first case, while no restraint was worn in the other case.

Pepperell et $a l^{3}$ reviewed all cases of road traffic accidents in pregnancy in the Australian state of Victoria between 1973 and 1975, and found 27 cases of fetal death, and a further five cases where the mother was also killed (table 2). These investigators observed that placental abruption was given as the cause for fetal death in 14 cases, and that in 12 of these cases seat belts were being worn. They speculated that the wearing of seat belts may predispose to placental abruption in the event of an accident. However it is noteworthy that in the five cases of combined maternal and fetal death, there were no instances where seat belts were being worn. In a more recent case report from Australia, Ford and Picker ${ }^{5}$ again implicate seat belt usage as the mechanism of injury to a fetus which sustained subarachnoid haemorrhage after a road traffic accident. The mother was wearing seat belts, and was free of significant injury, but it was speculated that the rapid

Table 2 Outcomes in 27 cases of automobile trauma in Victoria resulting in fetal death, from Pepperell et al (1977)

\begin{tabular}{llll}
\hline $\begin{array}{l}\text { Maternal injuries } \\
\text { sustained }\end{array}$ & $\begin{array}{l}\text { Number wearing } \\
\text { seatbelts }\end{array}$ & $\begin{array}{l}\text { Incidence of placental } \\
\text { abruption }\end{array}$ \\
\hline Nil & 6 & 2 & 2 (1 with seatbelt) \\
Bruising & 9 & 7 (1 unknown) & 9 \\
Fractures & 2 & 2 & 2 \\
$\begin{array}{l}\text { Multiple } \\
\text { trauma }\end{array}$ & 5 & 2 & 2 (neither in \\
Death & 5 & 0 & 2 seatbelts) \\
\hline
\end{tabular}


decelerative forces within the fetal cranium led to subarachnoid haemorrhage.

Atlay and Prysor-Jones ${ }^{6}$ describe a case of an unrestrained woman of 38 weeks gestation, who herself sustained a skull fracture, and 48 hours later was delivered of a stillborn infant with extensive subarachnoid haemorrhage.

Crosby $e t a l^{7}$ did a series of experiments with pregnant baboons in order to examine intrauterine pressures during impacts. They found that there was a brief increase in intrauterine pressure to around 10 times that in normal labour. The baboons were all restrained by either lap belts or three point restraints. Interestingly, the prevention of sudden forward flexion by the three point belt did not appreciably reduce intrauterine pressures.

It seems reasonable to conclude that seat belts are an effective measure in prevention of maternal injury, but that the possibility of fetal intracranial injury should be always borne in mind, even in the absence of maternal injury. Our case, along with many of those previously reported, emphasises the clinical observation that neonates are very prone to significant intracranial haemorrhage in association with closed head injury. Skull fractures can be diffcult to visualise on $x$ ray, more so when the skull is within the maternal pelvis. A high index of suspicion for fetal skull fracture is necessary, given the risks of associated intracranial haemorrhage.

Acetabular fracture in pregnancy is infrequently reported. There is a single case in Dyer and Barclay's series of a 24 year old woman at 16 weeks gestation. She was ultimately delivered by caesarean section at term. Evrard et $\mathrm{al}^{4}$ give a single case report of a 25 year old woman in the third trimester who was pulling out of her driveway and was killed when her vehicle was struck in the driver's door by a police vehicle travelling at $50 \mathrm{mph}$. At necropsy she had pelvic fractures, involving the left acetabulum and pubic ramus. The fetus had a depressed fracture of the right parietal bone. The cause of maternal death was shock due to intrathoracic and abdominal haemorrhage. Interestingly the mechanism of injury in Evrard's case is similar to the present case, with acetabular fracture following a side impact. This injury is presumably associated with great force, the lateral impact punching the head of the femur through the acetabulum into the pelvic cavity.
It is not surprising therefore, in the event of the fetal cranium being present in the pelvis (that is, in late pregnancy), that injury occurs. Antiintrusion bars being fitted to vehicle doors by many manufacturers should afford greater protection in the future.

The choice of route of delivery is an important factor in management of cases of maternal pelvic fracture. Dyer and Barclay ${ }^{2}$ note that a history of pelvic fracture certainly need not exclude vaginal delivery; more recently Bowdler et $a l^{8}$ note that some fetal injuries may be exacerbated by exposure to the forces of labour and delivery, and suggest that caesarean section should be considered in acute trauma.

\section{CONCLUSION}

Pelvic trauma in pregnancy is associated with a high incidence of fetal intracranial trauma. Fetal injuries include skull fracture and intracranial haemorrhage. Fetal skull fractures can be difficult to visualise on $x$ ray, especially when the head is in the maternal pelvis. Neonates are prone to significant intracranial haemorrhage in association with closed head injury.

Road traffic accidents account for the majority of trauma sustained in pregnancy. Seat belts are an effective measure in prevention of maternal injury, but there is a brief increase in intrauterine pressure during collisions which has been associated with placental abruption by some investigators. The rapid decelerative forces present during an accident add further to the risk of fetal intracranial haemorrhage.

A caesarean section should be considered in acute trauma, although a history of pelvic fracture does not exclude vaginal delivery.

1 Stafford PA, Biddinger PW, Zumwalt RE. Lethal intrauter-

2 Dyer IA, Barclay DL. Accidental trauma complicating pregnancy and delivery. Am J Obstet Gynecol 1962;83:90729.

3 Pepperell RJ, Rubinstein E, MacIsaac IA. Motor-car accidents during pregnancy. Med J Aust 1977;1:203-5.

4 Evrard JR, Sterner WO, Murray EJ. Fetal skull fracture from an automobile accident. Am J Forensic Med Pathol 1989; 10:232-4.

5 Ford RM, Picker RH. Fetal head injury following motor vehicle accident; an unusual case of intrauterine death. Aust NZ J Obstet Gynaecol 1989;29:72-3.

6 Atlay RD, Prysor-Jones D. Blunt external abdominal trauma Atlay RD, Prysor-Jones D. Blunt external abdominal trau

7 Crosby WM, Snyder RG, Snow CC, Hanson PG. Impact injuries during pregnancy. Am J Obstet Gynecol 1968;101: 100-8

8 Bowdler N, Faix RG, Elkins T. Fetal skull fracture and brain injury after a maternal automobile accident. J Reprod Med 1987;32:375-8. 